\title{
Trouble afoot: A review of common skin conditions of the feet and nails
}

CPD

Thomas Pitney, Jim Muir, Cong Sun

\section{Background}

Common foot and toenail problems may cause diagnostic and management difficulties and are often complicated by comorbid factors.

\section{Objective}

The aim of this article is to discuss common disorders of the skin and nails of the feet, regional physiological factors to consider and appropriate investigations and management.

\section{Discussion}

Cutaneous disorders of the feet and nails present significant diagnostic and management challenges given the considerable overlap of common signs and symptoms and regionally difficult management.
A NUMBER OF COMMON SKIN disorders have an altered and challenging appearance when arising on the foot. This is due to distinctive cutaneous features such as a characteristically thickened stratum corneum, which can be 10 times thicker on the sole when compared with other areas of skin, combined with unique environmental and physiological issues on the foot.

In this article, the authors review common presentations referred to a public outpatient dermatology department and an approach to each.

Complicating regional issues of gravitational dependency, lymphoedema, arterial and/or venous insufficiency, localised pressure or trauma and peripheral neuropathy can significantly alter clinical features and complicate investigations and management. Surgical intervention needs careful consideration because of compromised wound healing, with consideration of other modalities of treatment guided by histology if delayed healing is likely. Pre- and post-operative management of dependant oedema with external compression and elevation will optimise healing of surgical wounds.

The 'social history' of a foot is highly relevant. This includes the types of shoes worn (eg hot, wet or sweaty work boots or

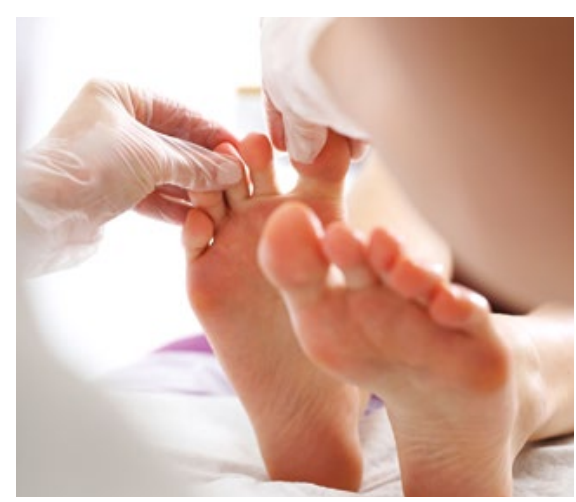

open, cool shoes; materials; adequate fit) and activities exposing feet to repetitive trauma or atypical infections associated with aquatic activities or travel.

\section{The red, scaly foot}

Psoriasis, tinea infections and dermatitis commonly present as a red, scaly foot. Well-defined borders and hyperkeratosis are more suggestive of psoriasis and tinea, and less suggestive of dermatitis. ${ }^{1}$ Vesicles are more commonly seen in pompholyx or acute contact dermatitis, less commonly associated with tinea and absent in psoriasis. ${ }^{1}$ Although not invariable, psoriasis and dermatitis tend to be bilateral, while unilateral involvement is more suggestive of tinea.

Supporting evidence for these conditions should be sought by completing a full skin examination, noting any other areas of involvement. Psoriasis has a predilection for palms, knees, elbows, natal cleft, nails or scalp. Tinea pedis is often accompanied by nail, palm, groin or body tinea. Thick fissuring of the heel is very suggestive of psoriasis. Dermatitis on the feet is highly variable in appearance depending on aetiology and provoking factors (eg irritant or allergic contact, pompholyx or hyperkeratotic 
variants). Patients with an atopic history are more predisposed to dermatitis of the feet than those with no atopic history. ${ }^{1}$ General management principles include avoidance of triggers such as heat, friction and sweating; avoidance of irritants; and consideration of cutaneous patch testing if indicated by history, persistence or cause remaining obscure. Initial investigations should include fungal scrapings to exclude tinea.

Punch biopsies can be used to assist diagnosis, but there is often considerable overlap in the histology of eczematous dermatitis and non-pustular palmoplantar psoriasis. Treatment of psoriasis and dermatitis is with potent topical steroid ointments such as betamethasone dipropionate $0.05 \%$ (with calcipotriol for psoriasis), with the addition of coal tar and salicylic acid ointments (typically $6 \%$ coal tar solution $+6 \%$ salicylic acid in sorbolene) if hyperkeratosis is significant. ${ }^{1}$ Ultraviolet (UV) light treatment with narrowband UVB may be effective for both conditions.

Refractory psoriasis may require systemic medication, such as acitretin or methotrexate, and a range of immunosuppressant and immunomodulating treatments used in dermatitis. For tinea infections, topical antifungals may be used for relatively asymptomatic infections; however systemic agents such as griseofulvin, itraconazole or terbinafine may be necessary for more severe and refractory cases. ${ }^{2}$ Terbinafine is keratinophilic and fungicidal, conferring additional benefit over fungistatic non-keratinophilic azoles. ${ }^{3}$

\section{Pustules on the sole of the foot}

Palmoplantar pustulosis presents as sterile pustules on palms and soles bilaterally and is associated with psoriasis in up to $25 \%$ of cases. It is strongly associated with smoking; up to $90 \%$ of patients are current or ex-smokers. ${ }^{1}$ Its course is often prolonged and refractory to treatment. ${ }^{1}$ Potent topical steroids with calcipotriol or tazarotene, crude coal tar, phototherapy, acitretin, methotrexate or immunosuppressants may be helpful. Inflammatory tinea infections may present with vesicopustules on soles, particularly at active margins.

\section{Interdigital intertrigo}

The combination of prolonged moisture and friction in interdigital spaces produces maceration, often complicated by secondary colonisation or infection and subsequent eczematisation due to staphylococci, streptococci, Pseudomonas species, Candida species or tinea. ${ }^{4}$ The presence of fissuring, vesiculation or pustulation is suggestive of secondary infection, which may lead to localised cellulitis. ${ }^{4}$ Uncommonly, inverse psoriasis may present in this manner. ${ }^{4}$ Bacterial swabs and scrapings for tinea are recommended to guide treatment. Keeping toe spaces clean and dry and treating secondary infection is usually effective; however, recurrence is fairly common.

\section{Discoloured nails}

Careful observation of nail pigment with good light and magnification will help inform diagnosis. Brown-black melanin (blue-grey if deeper in dermis) is seen in both benign and malignant processes. Subungual melanoma (Figure 1) is an uncommon entity that is not associated with UV exposure. ${ }^{5}$ It is the most common form of melanoma in people with dark skin colour. ${ }^{6}$ Clinical signs separating subungual melanoma from benign counterparts (eg benign longitudinal melanonychia) are the extension of pigmentation onto the proximal nail fold (Hutchinson's sign), heterogeneity of pigment colour, expansion of the width of pigment distribution or proximal growth. It can be amelanotic and may destroy the nail plate if advanced. Nail matrix biopsy is essential for diagnosis. ${ }^{6}$ In contrast, pigment in a subungual haematoma appears reddish brown and homogeneous and shows evidence of migration distally in the nail. ${ }^{6} \mathrm{~A}$ history of trauma or new footwear, and symmetrical signs in other nails, should be noted. Dermoscopy may show a purple-black colouration with a well-defined border, globular pattern or splinter haemorrhages or evidence of nail plate trauma. $^{7}$
Green pigment is suggestive of Pseudomonas species or Klebsiella species colonisation, usually resulting from onycholysis (separation of nail from nail bed), which provides a potential space for retained moisture and subsequent colonisation. ${ }^{1}$ Nightly soaking in solutions of one part vinegar to three parts water for 15 minutes daily as needed can resolve and prevent recurrence. ${ }^{1}$ There are also a number of conditions that can cause dystrophy of nails (Table 1 ).

Response to treatment may be slow as toenails grow an average of $1.62 \mathrm{~mm} /$ month (compared with $3.47 \mathrm{~mm} / \mathrm{month}$ for fingernails), ${ }^{8}$ and the growth rate decreases with age. Assessment of treatment response is prolonged, and compliance is often suboptimal.

\section{Basic principles of nail biopsy} This procedure will need to be performed in difficult cases. Anaesthesia of the nail unit is achieved through either a digital nerve block or paronychial block using local anaesthetic with adrenaline, which has been shown to be safe with no increased risk of necrosis. ${ }^{9}$ Biopsy technique relates to the anatomical location of the lesion. The nail bed, matrix and nail fold may be biopsied using elliptical excision or punch techniques. ${ }^{10}$ Either the entire nail or a proximal 'window' needs to be avulsed prior to removing the specimen. To minimise scarring and nail dystrophy, biopsies of the nail bed should be orientated longitudinally, while matrix biopsies



Figure 1. Subungual melanoma ${ }^{19}$

Reproduced with permission from DermNet NZ 


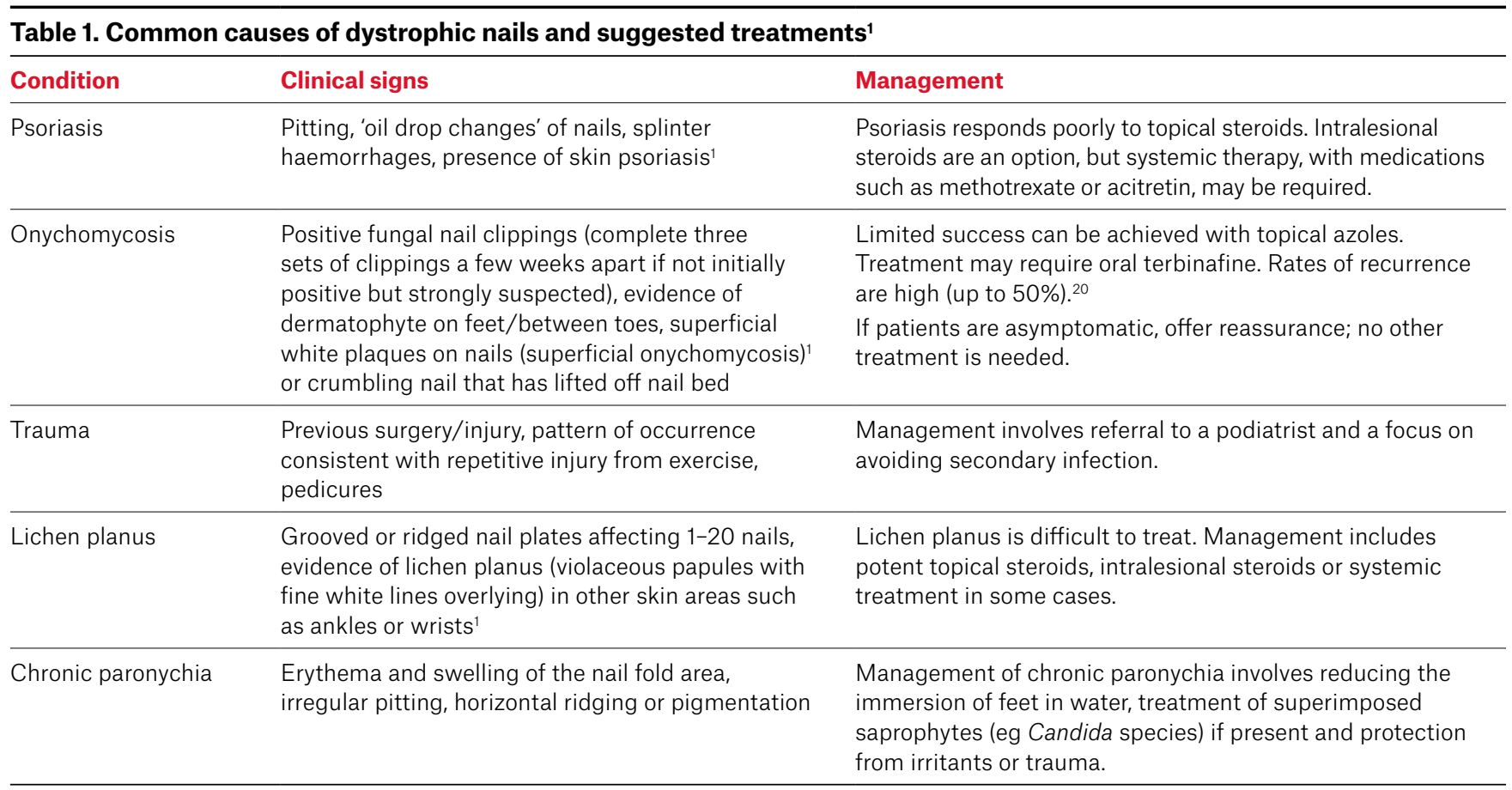

should be horizontal. ${ }^{10}$ If uncertainty exists, nail biopsies can be performed by a variety of providers including general practitioners, dermatologists and plastic, hand and general surgeons.

\section{Cracked heels}

Cracked and fissured heels may be associated with common dermatoses such as psoriasis, atopic dermatitis, ichthyoses and palmoplantar keratodermas or as an isolated feature, occurring when the thickened dry skin is cracked by the movement of the fat pad underneath the heel. ${ }^{11}$ Open-back shoes and sandals and increasing weight are predisposing factors. Treatment entails regularly using emollients, keratolytics and humectants such as urea and salicylic acid, and wearing enclosed footwear. ${ }^{11}$

\section{Pigmented lesions on the sole}

Tinea nigra (Hortaea werneckii), a mould infection acquired by soil contact, presents as a slow-growing tan-black pigmented macule on the sole, sometimes with slight scale, and an irregular but well-defined border. It may be confused with melanocytic lesions, especially acral melanoma. The diagnosis of tinea nigra is made on clinical grounds aided by dermoscopy (described as a 'non-melanocytic pattern of pigmented spicules'). ${ }^{12}$ Biopsy is not needed as the diagnosis can be easily confirmed by fungal skin scrapes and response to treatment with either topical antifungal ointment or topical combined benzoic acid and salicylic acid ointment. ${ }^{13}$

Acral lentiginous melanoma is a rare subtype of malignant melanoma found on distal skin, primarily the palms or soles, with the majority appearing on the feet. It accounts for $2-3 \%$ of melanomas and is significantly more prevalent in non-Caucasian individuals. ${ }^{14}$ Prognosis is often poorer as a result of delayed diagnosis and advanced stage at presentation. ${ }^{14}$ The characteristic dermoscopic finding of parallel ridge pigmentation (compared with the benign furrow pattern as shown in Figure 2) can be mimicked by benign conditions such as subcorneal haemorrhage. ${ }^{15}$ The treatment of acral lentiginous melanoma is by excision, with appropriate margins guided by lesion size and thickness. The resultant surgical defects can present significant challenges to repair. This surgery should only be undertaken by practitioners with a high level of surgical skill, with urgent referral if required.

\section{Keratinocytic malignancies}

Basal cell carcinoma is more prevalent in the head and neck region, and pedal disease is very uncommon. ${ }^{16}$ Squamous cell carcinoma is the most frequent cutaneous malignancy of the

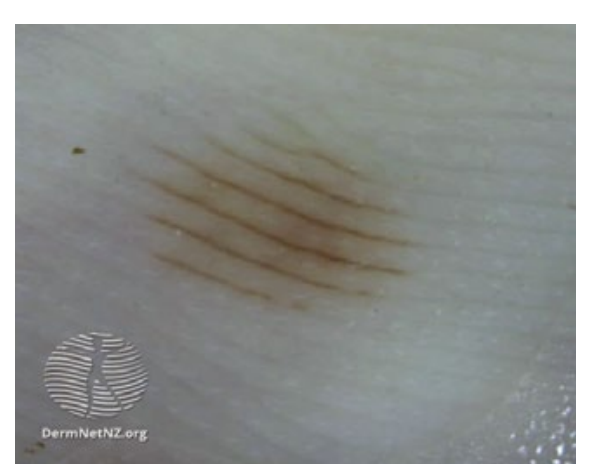

Figure 2. Benign parallel furrow pattern of pigmentation ${ }^{21}$

Reproduced with permission from DermNet NZ 
foot, occurring on the dorsal, acral and subungual regions. ${ }^{17}$ It occasionally arises from thermal burn scars, venous ulcers and osteomyelitic lesions known as Marjolin ulcers, which are often highly aggressive. ${ }^{18}$

Although some of the presentations mentioned in this article can have considerable overlap in appearance, careful observation of the important key features combined with the correct investigations will enable an accurate diagnosis and the appropriate management.

\section{Authors}

Thomas Pitney MBBS, Honorary Dermatology Registrar, The Mater Hospital, Qld. pitneythomas@gmail.com

Jim Muir MBBS, FACD, Director of Dermatology, The Mater Hospital, Qld

Cong Sun, final-year Doctor of Medicine student, The University of Queensland, Qld

Competing interests: None.

Funding: None.

Provenance and peer review: Commissioned, externally peer reviewed.

\section{References}

1. Burns T, Breathnach S, Cox N, Griffiths C. Rook's textbook of dermatology. 8th edn. Chichester, SXW: Wiley-Blackwell, 2010; p. 871-931, 1071-97.

2. Elston DM. Infectious diseases of the skin. Cheltenham, UK: Edward Elgar, 2011; p. 34-36.

3. El-Gohary M, van Zuuren EJ, Fedorowicz Z, et al. Topical antifungal treatments for tinea cruris and tinea corporis. Cochrane Database Syst Rev 2014;(8):CD009992. doi: 10.1002/14651858. CD009992.pub2.

4. Janniger CK, Schwartz RA, Szepietowski JC, Reich A. Intertrigo and common secondary skin infections. Am Fam Physician 2005;72(5):833-38.

5. Loh TY, Rubin AG, Brian Jiang SI. Basal cell carcinoma of the dorsal foot: An update and comprehensive review of the literature. Dermatol Surg 2017;42(4):464-70. doi: 10.1097/ DSS.0000000000000695.

6. Rtshiladze MA, Stretch JR, Stewart DA, Saw RP. Pigmented lesions of the nail bed - Clinical assessment and biopsy. Aust Fam Physician 2016;45(11):810-13.

7. Mun J-H, Kim G-W, Jwa S-W, et al. Dermoscopy of subungual haemorrhage: Its usefulness in differential diagnosis from nail-unit melanoma. Br J Dermatol 2013;168(6):1224-29. doi: 10.1111/ bjd.12209.

8. Yaemsiri S, Hou N, Slining MM, He K. Growth rate of human fingernails and toenails in healthy American young adults. J Eur Acad Dermatol Venereol 2010;24(4):420-23. doi: 10.1111/j.14683083.2009.03426.x

9. Kouba DJ, LoPiccolo MC, Alam M, et al. Guidelines for the use of local anesthesia in office-based dermatologic surgery. J Am Acad Dermatol 2016;74(6):1201-19. doi: 10.1016/j.jaad.2016.01.022.

10. Nevares-Pomales OW, Sarriera-Lazaro CJ, Barrera-Llaurador J, et al. Pigmented lesions of the nail unit. Am J Dermatopathol 2018:40(11):793-804. doi: 10.1097/ DAD.0000000000001106.
11. Ngan V. Cracked heel. Hamilton, NZ: DermNet NZ, 2006. Available at https://dermnetnz.org/topics/ cracked-heel [Accessed 6 March 2020].

12. Xavier MH, Ribeiro LH, Duarte H, Saraça G, Souza AC. Dermatoscopy in the diagnosis of tinea nigra. Dermatol Online J 2008;14(8):15.

13. Bonifaz A, Badali H, de Hoog GS, et al. Tinea nigra by Hortaea Werneckii, a report of 22 cases from Mexico. Stud Mycol 2008;61:77-82. doi: 10.3114/ sim.2008.61.07

14. Desai A, Ugorji R, Khachemoune A. Acral melanoma foot lesions. Part 1: Epidemiology, aetiology, and molecular pathology. Clin Exp Dermatol 2017;42(8):845-48. doi: 10.1111/ ced.13243.

15. Desai A, Ugorji R, Khachemoune A. Acral melanoma foot lesions. Part 2: Clinical presentation, diagnosis, and management. Clin Exp Dermatol 2018;43(2):117-23. doi: 10.1111/ ced.13323.

16. Loh $T Y$, Rubin AG, Jiang SI. Basal cell carcinoma of the dorsal foot: An update and comprehensive review of the literature. Dermatol Surg 2017;43(1):32-39. doi: 10.1097/ DSS.0000000000000900.

17. Knackfuss IG, Giordano V, Godoy-Santos AL, Fernandes NC, Camargo OP. Squamous cell carcinoma in the foot: Case series and literature review. Acta Ortop Bras 2018;26(2):108-11. doi: 10.1590/1413-785220182602187183.

18. Samitz MH, Lewis JE. Skin tumors of the lower extremities. Int J Dermatol 1978:17(7):558-67. doi: 10.1111/j.1365-4362.1978.tb05999.x.

19. DermNet NZ: All about the skin. Melanoma of the nail bed. Hamilton, NZ: DermNet NZ, 2011 Available at https://dermnetnz.org/topics/ melanoma-of-nail-unit-images [Accessed 6 March 2020].

20. Gupta AK, Lynch LE. Onychomycosis: Review of recurrence rates, poor prognostic factors, and strategies to prevent disease recurrence. Cutis 2004;74(1 Suppl):10-15.

21. Ashman N, Oakley A. Acral lentiginous melanoma dermoscopy. Hamilton, NZ: DermNet NZ, 2019. Available at https://dermnetnz.org/topics/acrallentiginous-melanoma-dermoscopy [Accessed 6 March 2020]. 